Article

\title{
Polysaccharides Release in a Laboratory-Scale Batch Hydrothermal Pretreatment of Wheat Straw under Rigorous Isothermal Operation
}

\author{
Felicia Rodríguez ${ }^{1,2}$ (D), Efrén Aguilar-Garnica ${ }^{2, *} \mathbb{D}$, Adrián Santiago-Toribio ${ }^{1,2}$ and Arturo Sánchez ${ }^{1, *(D)}$ \\ 1 Laboratorio de Futuros en Bioenergía, Centro de Investigación y de Estudios Avanzados del \\ IPN (CINVESTAV) Unidad Guadalajara, Av. del Bosque 1145, Col. El Bajío, Zapopan 45019, JA, Mexico; \\ felicia.rodriguez@edu.uag.mx (F.R.); adrian.santiago.t@gmail.com (A.S.-T.) \\ 2 Departamento de Ciencias Biotecnológicas y Ambientales, Universidad Autónoma de Guadalajara, \\ Av. Patria 1201, Col. Lomas del Valle, Zapopan 45129, JA, Mexico \\ * Correspondence: efren.aguilar@edu.uag.mx (E.A.-G.); arturo.sanchez@cinvestav.mx (A.S.)
}

check for

updates

Citation: Rodríguez, F.;

Aguilar-Garnica, E.; Santiago-Toribio,

A.; Sánchez, A. Polysaccharides

Release in a Laboratory-Scale Batch

Hydrothermal Pretreatment of Wheat

Straw under Rigorous Isothermal

Operation. Molecules 2022, 27, 26.

https://doi.org/10.3390/

molecules27010026

Academic Editors: Jalel Labidi and

Xabier Erdocia

Received: 24 November 2021

Accepted: 13 December 2021

Published: 22 December 2021

Publisher's Note: MDPI stays neutral with regard to jurisdictional claims in published maps and institutional affiliations.

Copyright: (C) 2021 by the authors. Licensee MDPI, Basel, Switzerland. This article is an open access article distributed under the terms and conditions of the Creative Commons Attribution (CC BY) license (https:// creativecommons.org/licenses/by/ $4.0 /)$.

\begin{abstract}
Hydrothermal pretreatment (HP) is an eco-friendly process for deconstructing lignocellulosic biomass (LCB) that plays a key role in ensuring the profitability of producing biofuels or bioproducts in a biorefinery. At the laboratory scale, HP is usually carried out under non-isothermal regimes with poor temperature control. In contrast, HP is usually carried out under isothermal conditions at the commercial scale. Consequently, significant discrepancies in the values of polysaccharide releases are found in the literature. Therefore, laboratory-scale HP data are not trustworthy if scale-up or retrofitting of HP at larger scales is required. This contribution presents the results of laboratoryscale batch HP for wheat straw in terms of xylan and glucan release that were obtained with rigorous temperature control under isothermal conditions during the reaction stage. The heating and cooling stages were carried out with fast rates ( 43 and $-40{ }^{\circ} \mathrm{C} / \mathrm{min}$, respectively), minimizing non-isothermal reaction periods. Therefore, the polysaccharide release results can be associated exclusively with the isothermic reaction stage and can be considered as a reliable source of information for HP at commercial scales. The highest amount of xylan release was $4.8 \mathrm{~g} / \mathrm{L}$ or $43 \%$ obtained at $180{ }^{\circ} \mathrm{C}$ and $20 \mathrm{~min}$, while the glucan release exhibited a maximum of $1.2 \mathrm{~g} / \mathrm{L}$ or $5.5 \%$. at $160{ }^{\circ} \mathrm{C} / 180{ }^{\circ} \mathrm{C}$ and $30 \mathrm{~min}$.
\end{abstract}

Keywords: hydrothermal pretreatment; wheat straw; lignocellulosic biomass; polysaccharides release

\section{Introduction}

Produced at a rate of 980 million tons per year, wheat straw (WS) is currently one of the most abundant agricultural residues worldwide [1]. This large availability, along with its high polysaccharides content (glucan and xylan mainly), makes WS a suitable lignocellulosic feedstock to produce bioethanol and other valuable products in biorefineries [2]. Pretreatment is the first stage in a biochemical platform biorefinery aimed at the extraction of soluble polysaccharides and the deconstruction of the lignocellulosic biomass (LCB) matrix [3].

A wide variety of pretreatment technologies have been proposed in the literature. Among them, hydrothermal pretreatment (HP) is an attractive option that can handle moisture-rich LCB with low energy requirements, making it suitable for large-scale applications $[4,5]$. The chemical reaction mechanism of HP uses the hydronium ions generated in situ by liquid hot water autoionization as a catalyst [6]. Therefore, HP is considered to be an environmentally friendly pretreatment. Batch-mode HP is carried out in three sequential stages: heating, reaction, and cooling. At the reaction stage, HP operates under saturated steam conditions at mid-range temperatures $\left(120-230^{\circ} \mathrm{C}\right)$ and reaction times between 0 and $3 \mathrm{~h}$ [7]. Below $220^{\circ} \mathrm{C}$, xylan hydrolysis is favored over glucan hydrolysis [8]. Consequently, the solid fraction of the pretreated biomass is enriched in cellulose whereas the liquid 
fraction is mainly composed of xylose and xylo-oligomers (XOOs). Usually, XOOs with a polymerization degree ranging from 2 to 12 units [9] are considered as feedstock for several commercial products in the cosmetic, food, and health industries [10]. Although xylan release into the liquid fraction as xylose and XOOs during HP is important, glucan release to glucose and gluco-oligomers (GOOs) must also be examined to obtain the whole picture of the pretreatment performance and to take advantage of the resulting fractions, both solid and liquid.

Xylan and glucan releases are usually reported as the results of HP conducted in batch-operation mode at the laboratory scale. For instance, Sidiras et al. [11], Ruiz et al. [12], Silva-Fernandes et al. [13], and Rossberg et al. [14] addressed polysaccharide release from WS as a function of solid loading, residence time, and temperature in batch reactors ranging from $100 \mathrm{~mL}$ to $3.75 \mathrm{~L}$. Although isothermal conditions are reached at the reaction stage of $\mathrm{HP}$, the heating and cooling rates are relatively slow. Usually, the heating time from the initial temperature to the desired reaction temperature varies from 15 to 80 min resulting in heating rates ranging from 2 to $7.1^{\circ} \mathrm{C} / \mathrm{min}$. In addition, the cooling rates for laboratoryscale batch HP have rarely been described. For instance, Sidiras et al. [11] reported a cooling stage pretreatment temperature decreasing from $160{ }^{\circ} \mathrm{C}$ to room temperature in $30 \mathrm{~min}$. Moreover, polysaccharide release during these long periods of heating and cooling is not distinguished from the corresponding release achieved in isothermal conditions. This might be the cause of significant discrepancies in the results of laboratory-scale HP available in the literature. For instance, Ruiz et al. [12] reported 39\% as a maximum value for xylan release at $180{ }^{\circ} \mathrm{C}$ in a $0.6 \mathrm{~L}$ stirred batch reactor, while Sidiras et al. [11] reached $76 \%$ using a $3.7 \mathrm{~L}$ stirred batch reactor. Therefore, data related to the quantities of xylan release under HP regimes provided in the literature are not consistent.

Another laboratory-scale HP result with a high degree of uncertainty is the reaction time or residence time. According to Prunescu et al. [15], Rodriguez et al. [16], and Makishima et al. [17], shorter residence times than those reported for batch laboratory-scale $\mathrm{HP}$ studies are required to achieve similar amounts of released polysaccharides for HP conducted at the industrial or semi-pilot scale in continuous operation. The uncertainty in the residence time could imply significant readjustments in the biomass residence time systems, issues that Sieves and Stickel [18] and Jaramillo and Sanchez [19] reported as a technological challenge due to the rheological properties of the biomass. This might also represent a clear scaling-up problem for HP, as recently reported by Yue et al. [20]. Therefore, the results obtained at laboratory-scale HP are not trustworthy if needed for retrofitting or scaling-up purposes of HP at larger scales. This is because the continuous operation of an HP at commercial scales is governed by an isothermal regime. Heating is usually provided by saturated steam, while cooling is almost instantaneously achieved after steam explosion.

The effects of heating and cooling times in HP have been previously analyzed using the severity factor (SF) and modified severity factor (MSF) [21]. However, Ilanidis et al. [22] and Yu et al. [23] reported significant differences in terms of xylan release among pretreatments performed at the same SF with $1 \mathrm{~L}$ and $5000 \mathrm{~L}$ capacity reactors. Additionally, Conrad et al. [24] reported an SF interval (between four and five) in which linear proportionality with respect to hemicellulose conversion was not observed in $30 \mathrm{~mL}$ reactors. Moreover, no experimental validation of the MSF for short heating periods has been reported. Instead, the heating time or heating rates is commonly considered as the key operating condition in thermochemical LCB pretreatments $[25,26]$.

In this contribution, experimental results expressed as polysaccharides release or, more specifically, xylan and glucan releases were obtained from a laboratory-scale batch HP of WS carried out under an overall isothermal operation. The isothermal operation was possible because both the heating and the cooling periods were very short or the heating and cooling rates were fast. Consequently, polysaccharides release can be considered negligible during both the heating and the cooling stages. The fast heating rate was induced by a fluidized sand bath, while fast cooling was achieved by the immersion of 
the batch HP reactor into a water bath. The main difference between the results described in this contribution and those already available is that they were obtained in rigorous isothermal conditions with a precise characterization of temperature trajectories in terms of heating and cooling rates and periods, as well as reaction times. Therefore, the results presented here could be considered as a basis for scaling-up or retrofitting HP calculations at commercial scales oriented to XOOs and GOOs production.

\section{Results and Discussion}

\subsection{Characterization of Temperature Behavior for HP Experiments}

The set of reaction temperatures and times, and heating and cooling times/rates for the HP experiments are compiled in Table 1. Temperature profiles for the longest reaction times are shown in Figure 1a.

Table 1. Characterization of reaction temperature trajectories.

\begin{tabular}{cccc}
\hline Reaction Temperatures $\left({ }^{\circ} \mathbf{C}\right)$ & Reaction Times (min) & $\begin{array}{c}\text { Mean Heating Times (min), } \\
\text { Rates }\left({ }^{\circ} \mathbf{C} / \mathbf{m i n}\right)\end{array}$ & $\begin{array}{c}\text { Mean Cooling Times (min), } \\
\text { Rates }\left({ }^{\circ} \mathbf{C} / \mathbf{m i n}\right)\end{array}$ \\
\hline 150 & $0,20,30,40,60$ & $\approx 3,43$ & $\approx 3,-17$ \\
160 & $0,30,60$ & $\approx 5,28$ & $\approx 4,-15$ \\
180 & $0,5,10,20,30,40$ & $\approx 6,27$ & $\approx 4,-20$ \\
200 & $0,5,10,15,40,60$ & $\approx 6,30$ & $\approx 3,-33$ \\
220 & $0,15,20,30$ & $\approx 6,34$ & $\approx 3,-40$ \\
\hline
\end{tabular}

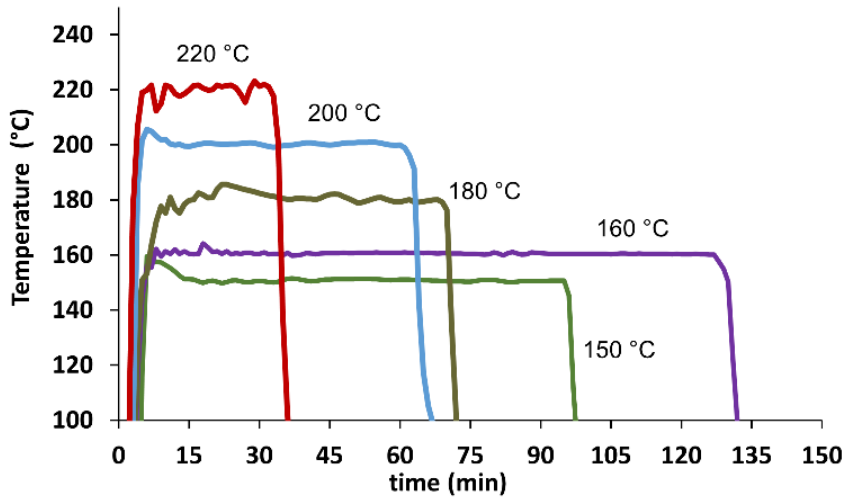

(a)

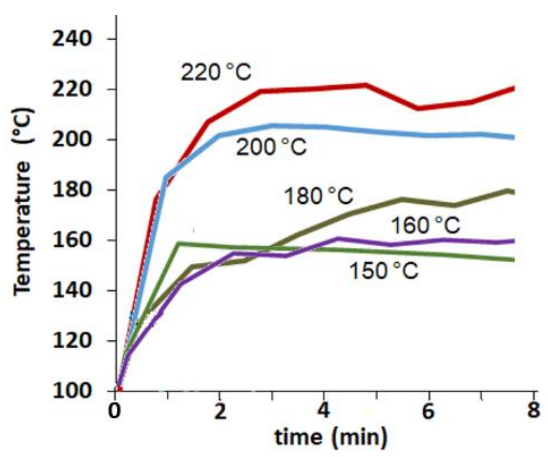

(b)

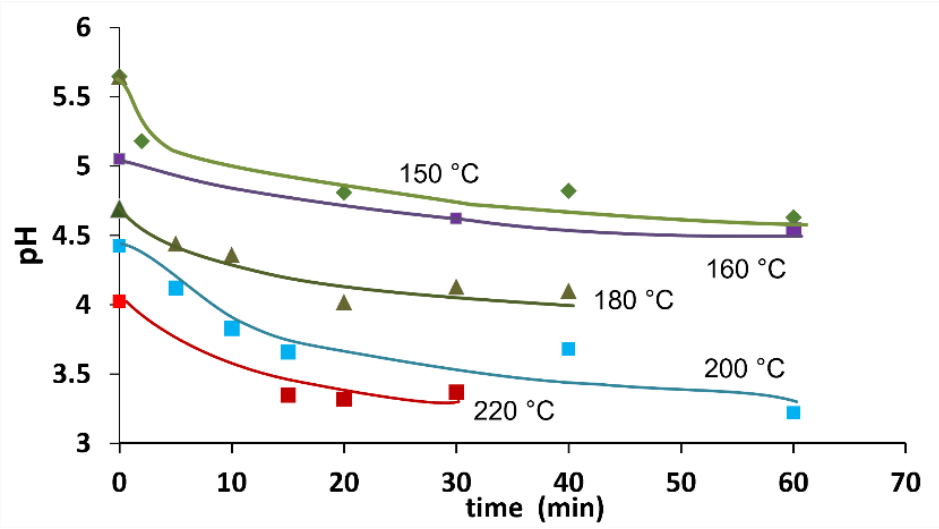

(c)

Figure 1. (a) Typical behavior of reaction temperature and (b) heating ramps in HP experiments of WS at the longest reaction times. (c) Mean $\mathrm{pH}$ profiles in HP experiments of WS as a function of time. The continuous lines are the tendencies of the experimental $\mathrm{pH}$ values. 
The mean heating times ranged from $3 \mathrm{~min}$ in the HP experiments conducted at 150 and $160^{\circ} \mathrm{C}$ to 6 min at higher temperatures. As shown in Figure 1b, isothermal reaction temperatures were reached after $3 \mathrm{~min}$ from $100{ }^{\circ} \mathrm{C}$.

Furthermore, the mean heating rates were between 11 and $43{ }^{\circ} \mathrm{C} / \mathrm{min}$. Heating using a sand bath was compared to other techniques such as the steam chamber. For instance, Trajano et al. [27] reported a thermal study that revealed that the steam chamber offers better heat transfer performance compared to a sand bath. Nevertheless, these conclusions were obtained for a micro-scale reactor $(10 \mathrm{~mL})$. In addition, Shi et al. [28] concluded that the heating-up and cooling-down times for HP carried out by microwaves remain very close to those obtained for HP heated with a sand bath.

Regarding the cooling stage, the obtained mean cooling times ranged from 3 to 5 min with mean cooling rates from -15 to $-40{ }^{\circ} \mathrm{C} / \mathrm{min}$. Although the cooling stage in large-scale $\mathrm{HP}$ in continuous operation is almost instantaneous, the cooling-down strategy of this work is three times faster than those previously described [11].

\subsection{Analysis of $p H$ Values in the HP Experiments}

The dynamic evolution of $\mathrm{pH}$ at different reaction times is shown in Figure 1c. Generally, $\mathrm{pH}$ decreases when reaction temperature increases and remains bounded within 3.3 and 5.6. For reaction temperatures of 150 and $160{ }^{\circ} \mathrm{C}$, the $\mathrm{pH}$ was between 4.6 and 5.6 , an interval in which toxic inhibitors, such as furfural, and 5-hydroxymethylfurfural are not produced as a consequence of the poor production of monomeric sugars from soluble oligosaccharides [3]. The absence of furfural and HMF was confirmed with HPLC analysis. In addition, $\mathrm{pH}$ values at 180 to $220{ }^{\circ} \mathrm{C}$ showed similar patterns to those reported in reactions carried out in $3.7 \mathrm{~L}$ Parr reactors [5,11]. Additionally, a relation of $-0.018 \pm 0.003 \mathrm{pH}$ units $/{ }^{\circ} \mathrm{C}$ was found when considering the isothermal reaction stage between 150 and $220^{\circ} \mathrm{C}$.

\subsection{Analysis and Discussion of Xylan and Glucan Release Results}

Figure 2 shows the xylan and glucan releases as monomers $\left(\% X_{m r}\right.$ and $\% G_{m r}$, respectively), whereas Figure 3 describes the corresponding values of the xylan and glucan releases as monomers and oligomers $\left(\% \mathrm{X}_{\mathrm{mor}}\right.$ and $\% \mathrm{G}_{\mathrm{mor}}$, respectively.) Numerical data are shown in Table 2.

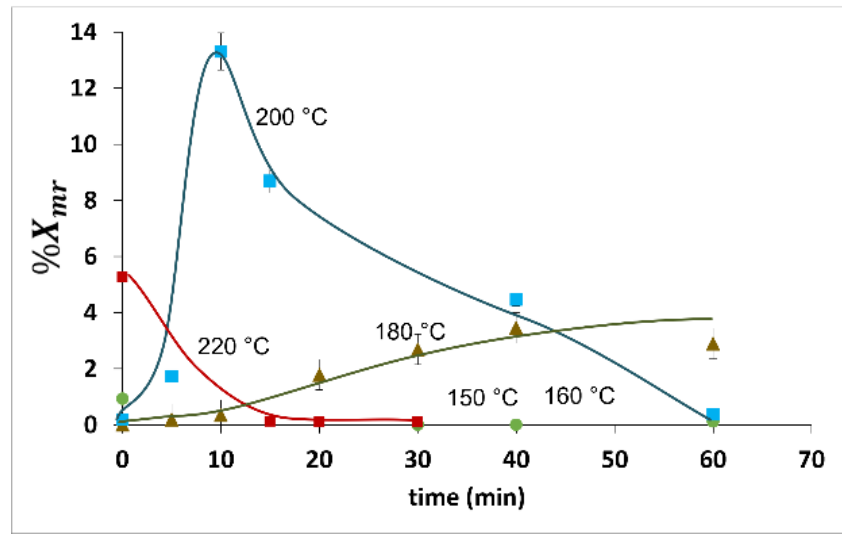

(a)

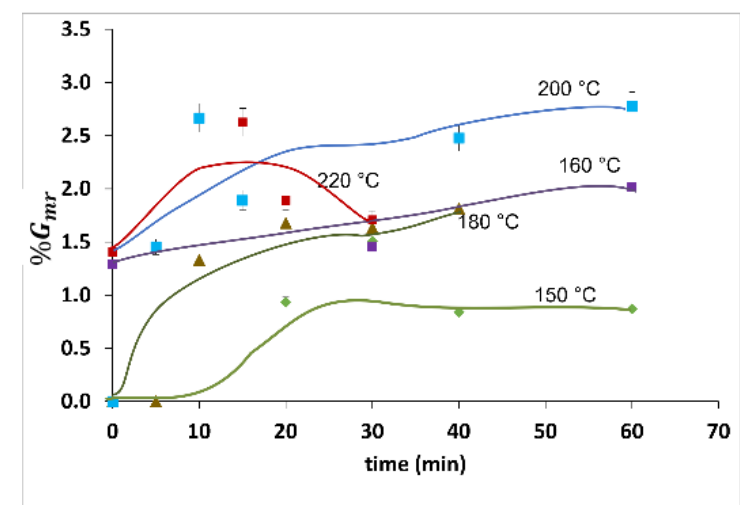

(b)

Figure 2. Polymers release to monomers as a function of isothermal reaction time and temperature of (a) xylose $\left(\% \mathrm{X}_{\mathrm{mr}}\right)$ and $(\mathbf{b})$ glucose $\left(\% \mathrm{G}_{\mathrm{mr}}\right)$. Data points represent the averages of 3 experiments. Error bars represent standard uncertainties. 


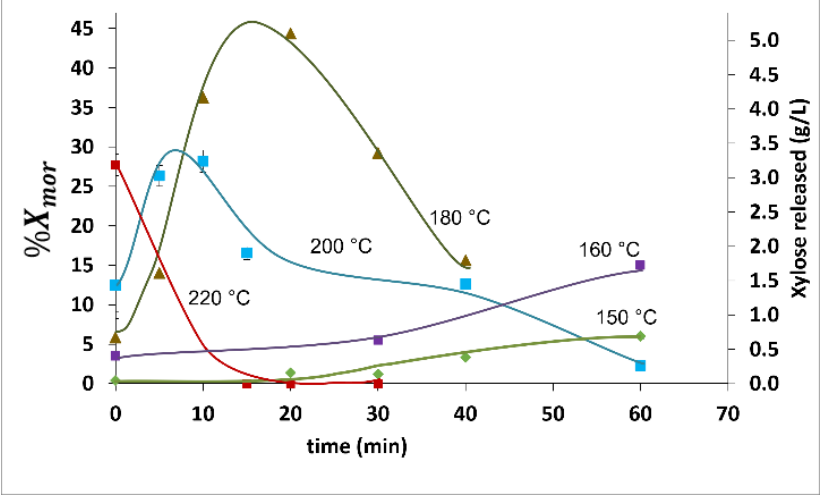

(a)

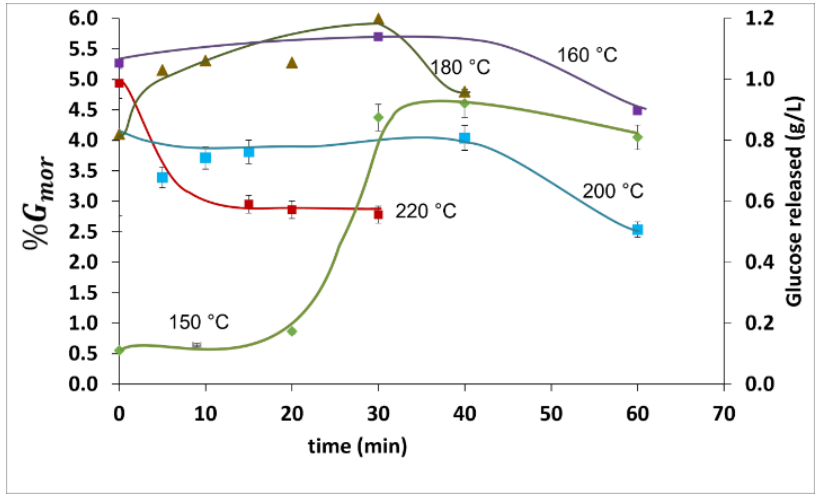

(b)

Figure 3. Polymers release to monomers and oligomers of (a) xylose $\left(\% \mathrm{X}_{\mathrm{mor}}\right)$ and $(\mathbf{b})$ glucose $\left(\% \mathrm{G}_{\mathrm{mor}}\right)$. Data points represent the averages of 3 experiments. Error bars represent standard uncertainties.

Table 2. Results of laboratory-scale batch HP experiments.

\begin{tabular}{|c|c|c|c|c|c|c|}
\hline Reaction Temperature $\left({ }^{\circ} \mathrm{C}\right)$ & Reaction Time (min) & $\% \mathbf{X}_{\mathrm{mr}}$ & $\% G_{m r}$ & $\begin{array}{c}\% X_{\text {mor }} / \\
\text { Xylan Release }\left(\frac{g}{L}\right)\end{array}$ & $\begin{array}{c}\% G_{\text {mor }} / \\
\text { Glucan Release }\left(\frac{g}{L}\right)\end{array}$ & $\mathrm{pH}$ \\
\hline 150 & 0 & 0.010 & 0.01 & $0.40 / 0.00$ & $0.60 / 0.10$ & 5.3 \\
\hline 150 & 20 & 0.020 & 0.93 & $1.4 / 0.20$ & $0.90 / 0.20$ & 4.8 \\
\hline 150 & 30 & 0.030 & 1.5 & $1.2 / 0.10$ & $5.3 / 1.1$ & 4.8 \\
\hline 150 & 40 & 0.030 & 0.84 & $3.3 / 0.40$ & $4.6 / 0.90$ & 4.8 \\
\hline 150 & 60 & 0.13 & 0.87 & $6.0 / 0.70$ & $4.1 / 0.81$ & 4.6 \\
\hline 160 & 0 & 0.010 & 1.3 & $3.5 / 0.40$ & $5.3 / 1.1$ & 5.1 \\
\hline 160 & 30 & 0.020 & 1.5 & $5.5 / 0.60$ & $5.5 / 1.2$ & 4.4 \\
\hline 160 & 60 & 0.080 & 2.0 & $15 / 1.7$ & $4.5 / 0.90$ & 4.5 \\
\hline 180 & 0 & 0.010 & 0.010 & $5.9 / 0.70$ & $4.1 / 0.80$ & 4.7 \\
\hline 180 & 5 & 0.19 & 0.010 & $14 / 1.6$ & $5.2 / 1.0$ & 4.4 \\
\hline 180 & 10 & 0.34 & 1.3 & $36 / 4.0$ & $5.3 / 1.1$ & 4.4 \\
\hline 180 & 20 & 1.8 & 1.7 & $43 / 4.8$ & $5.3 / 1.1$ & 4.0 \\
\hline 180 & 30 & 2.7 & 1.6 & $29 / 3.3$ & $5.5 / 1.2$ & 4.1 \\
\hline 180 & 40 & 3.5 & 1.8 & $16 / 1.7$ & $4.8 / 1.0$ & 4.1 \\
\hline 200 & 0 & 0.19 & 0.010 & $13 / 1.4$ & $4.1 / 0.80$ & 4.4 \\
\hline 200 & 5 & 1.7 & 1.5 & $26 / 2.9$ & $3.4 / 0.70$ & 4.1 \\
\hline 200 & 10 & 13 & 2.7 & $28 / 3.1$ & $3.7 / 0.70$ & 3.8 \\
\hline 200 & 15 & 8.0 & 1.9 & $17 / 1.8$ & $3.8 / 0.80$ & 3.7 \\
\hline 200 & 40 & 4.5 & 2.5 & $13 / 1.4$ & $4.0 / 0.80$ & 3.8 \\
\hline 200 & 60 & 0.37 & 2.8 & $2.3 / 0.3$ & $2.5 / 0.50$ & 3.5 \\
\hline 220 & 0 & 5.3 & 1.4 & $28 / 3.1$ & $4.9 / 1.0$ & 4.0 \\
\hline 220 & 15 & 0.12 & 2.6 & $0.20 / 0.00$ & $3.0 / 0.60$ & 3.4 \\
\hline 220 & 20 & 0.090 & 1.9 & $0.20 / 0.00$ & $2.9 / 0.60$ & 3.3 \\
\hline 220 & 30 & 0.11 & 1.7 & $0.00 / 0.00$ & $2.8 / 0.60$ & 3.4 \\
\hline
\end{tabular}

Figure 3 shows both the weight/weight percentage and grams per liter of the reaction products to enable comparison with data already available in the literature. Notice that $\% X_{m r}$ and $\% G_{m r}$ were negligible in all the HP experiments conducted at 150 and $160{ }^{\circ} \mathrm{C}$. Additionally, $\% \mathrm{X}_{\text {mor }}$ and $\% \mathrm{G}_{\text {mor }}$ for the HP experiments at $t=0$ conducted at $150{ }^{\circ} \mathrm{C}$ were below $0.20 \mathrm{~g} / \mathrm{L}$. This amount is ten times lower than the value reported by Carvalheiro et al. [29] under similar reaction conditions.

The $\% X_{\text {mor }}$ and $\% G_{m o r}$ were $6.0(0.70 \mathrm{~g} / \mathrm{L})$ and $4.1(0.81 \mathrm{~g} / \mathrm{L})$, respectively, at $150{ }^{\circ} \mathrm{C}$ after $60 \mathrm{~min}$. Surprisingly, $\% \mathrm{X}_{\text {mor }}$ exhibited a significant increase to $15 \%$, or equivalently $1.7 \mathrm{~g} / \mathrm{L}$, when increasing the reaction temperature by $10{ }^{\circ} \mathrm{C}$, whereas the increase in $\% \mathrm{G}_{\text {mor }}$ was barely perceptible. In addition, a decrease in $\% \mathrm{G}_{\text {mor }}$ at 150 and $160{ }^{\circ} \mathrm{C}$ was observed before the end of the reaction (i.e., at $60 \mathrm{~min}$ ). This might represent the degradation of glucan released from highly reactive glucans. By comparison, this decrease was not observed for xylan because the rate of xylan released at 150 and $160{ }^{\circ} \mathrm{C}$ was greater than the production of degradants. 
For higher temperatures (i.e., from 180 to $220^{\circ} \mathrm{C}$ ) at $t=0$, changes in the $\% \mathrm{G}_{\text {mor }}$ were proportional to changes in the reaction temperature. In contrast, monotonous decreases in the $\% \mathrm{X}_{\text {mor }}$ and $\% \mathrm{G}_{\mathrm{mor}}$ were registered at $220{ }^{\circ} \mathrm{C}$, suggesting a relatively high degradation rate of both polymers regarding the polymers released. These results are similar to those of Carvalheiro et al. [29] and Silva-Fernandes et al. [13], who reported degradation above $220{ }^{\circ} \mathrm{C}$.

$\mathrm{HP}$ exhibited the largest value of $\% \mathrm{X}_{\mathrm{mor}}$ at $180{ }^{\circ} \mathrm{C}$ and $20 \mathrm{~min}$. This value was $4.8 \mathrm{~g} / \mathrm{L}$, equivalent to $\% X_{\text {mor }}=43$, which is less than $2 \%$ of $\% X_{m r}$ according to the findings depicted in Figure 3. Similar operating conditions (i.e., $180{ }^{\circ} \mathrm{C}$ and $18 \mathrm{~min}$ ) were reported by Rodriguez et al. [16] for HP experiments carried out at a semi-pilot scale in a continuous tubular reactor for diverse LCB feedstock. In that contribution, short heating times at the input of the reactor were observed and, due to steam explosion at the output, short cooling times were also reported, as in the present contribution. In addition, Rodriguez et al. [16] observed an evident decrease in $\% \mathrm{X}_{\text {mor }}$ at $180{ }^{\circ} \mathrm{C}$ and $40 \mathrm{~min}$, which was also observed in this study as a clear indicator of degradation products.

Th maximum value of $\% \mathrm{X}_{\text {mor }}$ at $200{ }^{\circ} \mathrm{C}$ was 28 (or $3.1 \mathrm{~g} / \mathrm{L}$ ) with a reaction time of $10 \mathrm{~min}$. This sample recorded the highest $\% \mathrm{X}_{\mathrm{mr}}(13)$, providing low glucan degradation. In addition, the maximum value of $\% X_{\text {mor }}$ at $200{ }^{\circ} \mathrm{C}$ reported here (i.e., $28 \mathrm{~g} / \mathrm{L}$ ) is higher than that obtained by Silva-Fernandes et al. [13], which is close to $20 \mathrm{~g} / \mathrm{L}$, and that was obtained at $210{ }^{\circ} \mathrm{C}$ in a $0.6 \mathrm{~L}$ stirred batch reactor with a heating rate equal to $6.2{ }^{\circ} \mathrm{C} / \mathrm{min}$, which is five- lower than the heating rate that is reported in this contribution (see Table 1). Additionally, a \% $X_{\text {mor }}$ decrease was observed from 3.1 to $1.8 \mathrm{~g} / \mathrm{L}$ after $10 \mathrm{~min}$, which is a symptom of a higher rate of degradant production.

Conducting a deeper analysis of the $\% \mathrm{G}_{\mathrm{mor}}$ and $\% \mathrm{G}_{\mathrm{mr}}$ results, the following findings were registered: First, $\% \mathrm{G}_{\text {mor }}$ in the HP experiments conducted at $t=0$ for samples pretreated at 160 to $220{ }^{\circ} \mathrm{C}$ was between 0.80 and $1.2 \mathrm{~g} / \mathrm{L}$. Additionally, the maximum value of $\% \mathrm{G}_{\mathrm{mor}}(1.2 \mathrm{~g} / \mathrm{L}$, which is equivalent to $5.5 \%)$ was observed in the experiments at 160 and $180{ }^{\circ} \mathrm{C}$ conducted for $30 \mathrm{~min}$. This maximum value is only $0.2 \%$ higher than that obtained in the $\mathrm{HP}$ experiments at $t=0$ conducted at $160{ }^{\circ} \mathrm{C}$. In addition, similar concentrations of $\% \mathrm{G}_{\mathrm{mor}}$ at 200 and $60 \mathrm{~min}$; and at $220^{\circ} \mathrm{C}$ and 15, 20, and $30 \mathrm{~min}$ could be due to the highly reactive cellulose. $\% \mathrm{G}_{\mathrm{mor}}$ is lower than $\% \mathrm{X}_{\text {mor }}$ because, as stated in the Introduction, this is a common behavior observed in HP because it favors xylan release. The results of $\% \mathrm{G}_{\mathrm{mr}}$ span from $0 \%$ to $2.7 \%$ (from 0 to $0.54 \mathrm{~g} / \mathrm{L}$ ). These relatively low values confirm that HP does not hydrolyze glucan. Furthermore, the $\% \mathrm{G}_{\mathrm{mr}}$ values do not show increases proportional to temperature as in other pretreatments, such as acid-catalyzed, that have been previously reported to favor glucan hydrolysis. In this contribution, the resulting glucan monomers may be produced from superficial, fast-reactive glucans on WS.

The discrepancies between the different polymer releases described in this contribution and those reported previously might be due to the fast heating-up and cooling-down periods of the experiments that do not contribute to polymer release. Although the success of hydrothermal pretreatment does not exclusively involve the release of xylan, XOOs has a potential market niche, and a good correlation with enzymatic saccharification has also been observed [30,31]. Furthermore, to have HP operating at rigorous isothermal conditions is fundamental to reach hydrogen and ethanol co-production via dark fermentation [32] and other eco-friendly fuel precursors [33].

\section{Materials and Methods}

\subsection{Wheat Straw Characterization}

Furrow-irrigated WS (Triticum aestivum L.; cultivar. Urbina S2007) was kindly supplied by a private agribusiness from Tepatitlán, Jalisco, Mexico $\left(20^{\circ} 49^{\prime} 0.91^{\prime \prime} \mathrm{N}, 102^{\circ} 45^{\prime} 48.49^{\prime \prime} \mathrm{W}\right)$ with the following initial composition: glucan (41.32\%) and xylan (19.54\%). Compositional results were obtained according to the NREL laboratory analytical procedures [34]. The WS was harvested using conventional WS harvesting equipment and subsequently milled with an agricultural hammer mill (Azteca, Guadalajara Jal., México) equipped with a 1/2" 
sieve. WS particles of 14-18 Tyler mesh $(1.41 \mathrm{~mm}$ to $1.00 \mathrm{~mm})$ were collected with a TestMaster Testing Screen (Gilson, Lewis Center OH, USA). This size distribution was chosen to maximize sugar recovery (Rojas-Rejon and Sanchez [35]).

\subsection{Experimental HP Runs}

The HP experiments were carried out with WS samples $(8 \mathrm{~g})$ mixed with water $(150 \mathrm{~mL})$ in a tailor-made batch reactor of carbon steel SCG-80 with a 2 in diameter and 6in length. The reactor was not provided with a stirring system to reproduce the poor mixing conditions described in continuous large-scale HP operations [18].

Reactor temperatures during the heating-up, reaction, and cooling-down stages of the $\mathrm{HP}$ experiments were measured through a thermowell with a Pt-100 RTD and recorded with I-7015 and I-7188E2 acquisition modules coupled to a data logger (ICPDAS, Shangai, China). Pressure within the reactor was measured with a $0-4 \mathrm{MPa} \pm 2.00 \%$ manometer (Instrutek, Guadalajara Jal., Mexico). The relationship between the temperature and the pressure was continuously monitored for temperature data validation.

Experimental runs started at $20^{\circ} \mathrm{C}, \mathrm{pH}=5.6$, and heating was provided by a TBSL12 fluidized sand bath (Accurate Thermal Systems, Hainesport, NJ, USA) equipped with automatic temperature control.

Although positive effects were reported when using several heating steps [36], a fast heating-up strategy was used to emulate large-scale HP operating conditions where the biomass is instantly in contact with steam at high temperatures.

The following temperature set points were evaluated during the reaction stage of the HP: $150,160,180,200$, and $220^{\circ} \mathrm{C}$. This interval of temperatures was previously identified to achieve high monomer yields and hemicellulose recovery in the HP of WS [29]. Reaction times between 0 and $60 \mathrm{~min}$ were registered after the reactor temperature reached the desired set point. Experiments labelled " $t=0$ " are those that were driven to the desired temperature set point, and then they were immediately cooled down. Once the reaction time finished, the reactor was removed from the sand bath and cooled down in a water bath to $100^{\circ} \mathrm{C}$, which was considered the final HP temperature. A total of 72 experiments were carried out, including repetitions of the different reaction temperature and reaction time combinations that are shown in Table 1.

\subsection{Analysis on Xylan and Glucan Release}

The strategy to quantify and report xylan and glucan release is based on the general reaction pathway of the hydrothermal pretreatment shown in Figure 4.

This pathway assumes that the masses of xylan $\left(m_{X y l a n}^{0}\right)$ and glucan $\left(m_{\text {Glucan }}^{0}\right)$ in the WS at the beginning of the HP experiments are known and that the solid and liquid fraction produced after the HP can be recovered and analyzed qualitatively and quantitatively, respectively. One assumption that supports this pathway is that both unreacted xylan and glucan conform to the solid fraction. Another assumption is that monosaccharhplides (i.e., xylose and glucose), XOOs, furfural, and HMF are the main components of the liquid fraction. This fraction was analyzed after room temperature was reached as follows: first, it was centrifuged with a Heraeus Pico 17 centrifuge (ThermoFisher, Waltham, MA, USA) at 13,000 rpm for $5 \mathrm{~min}$; then it was filtrated with a $45 \mu \mathrm{m}$ acrodisc syringe filter. In addition, the $\mathrm{pH}$ of the filtrate was measured using an Orion Star A211 benchtop pH meter (ThermoFisher, Waltham MA, USA).

The concentrations of the degradation compounds (i.e., furfural and HMF) in the liquid phase were measured using the 2695 HPLC (Waters Alliance, Milford MA, USA). The xylose and glucose concentrations in the liquid fraction were determined via a YSI 2700D biochemistryanalyzer (Mashall Scientific, Hampton, NH, USA). Then the mass of xylose $m_{\text {Xylose }}^{H T}$ and the mass of glucose $m_{\text {Glucose }}^{H T}$ were computed. The percentage of 
xylan $\left(\% \mathrm{X}_{\mathrm{mr}}\right)$ and glucan $\left(\% \mathrm{G}_{\mathrm{mr}}\right)$ release as monomers after HP were computed with the following equations:

$$
\begin{aligned}
& \% X_{m r}=100\left(\frac{m_{\text {Xylose }}^{H T}}{m_{\text {Xylan }}^{0}} \frac{1}{F E X}\right) \\
& \% G_{m r}=100\left(\frac{m_{\text {Glucose }}^{H T}}{m_{\text {Glucan }}^{0}} \frac{1}{F E G}\right)
\end{aligned}
$$

where FEX $=1.13$ and FEG $=1.11$ are the stoichiometric factors between the monomers and oligomers of xylan and glucan, respectively.

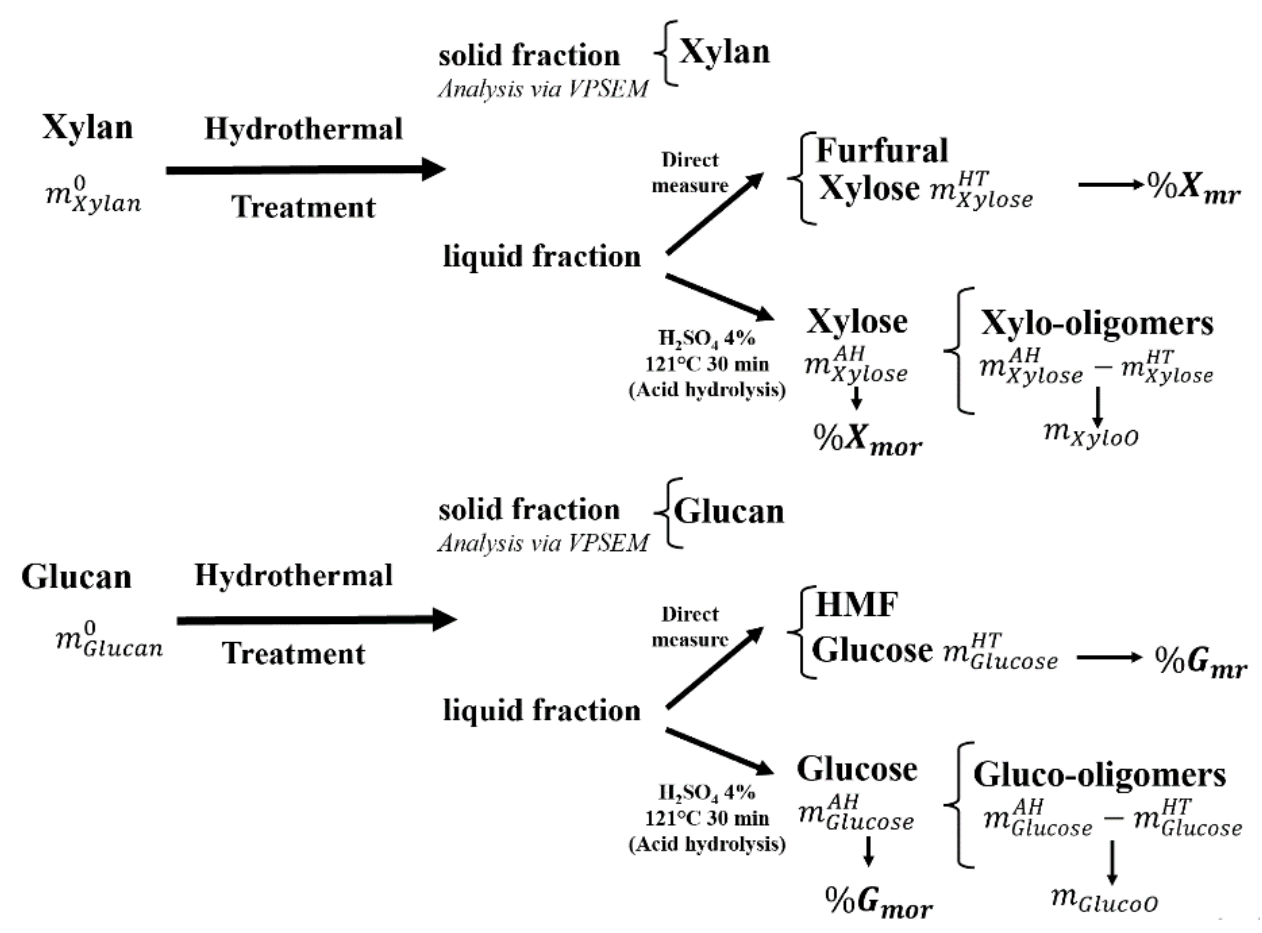

Figure 4. Xylan and glucan release pathways. $\% \mathrm{X}_{\mathrm{mr}}$ and $\% \mathrm{G}_{\mathrm{mr}}$ are the monomers released from xylan to xylose and from glucan to glucose, respectively, while $\% X_{\text {mor }}$ and $\% G_{m o r}$ are the polymers released from xylan to both xylose and XOOs and from glucan to both glucose and GOOs, respectively.

In addition, to quantify the released oligomers present in the liquid fraction that was hydrolyzed in the presence of $\mathrm{H}_{2} \mathrm{SO}_{4}(4 \%)$ at $121{ }^{\circ} \mathrm{C}$ for $30 \mathrm{~min}$. Later, the xylose and glucose concentrations were determined using a YSI 2700D biochemistryanalyzer (Mashall Scientific, Hampton NH, USA). that was applied to the after-hydrolysis (AH) liquid. Then, the mass of xylose $\left(m_{X y l o s e}^{A H}\right)$ and the mass of glucose $\left(m_{\text {Glucose }}^{A H}\right)$ were computed. The masses of oligomers could be calculated with the following expressions:

$$
\begin{gathered}
m_{\text {XyloO }}=m_{\text {Xylose }}^{\text {AH }}-m_{\text {Xylose }}^{H T} \\
m_{\text {GlucoO }}=m_{\text {Glucose }}^{\text {AH }}-m_{\text {Glucose }}^{H T}
\end{gathered}
$$

Finally, the polymers released from xylan to both xylose and XOOs $\left(\% \mathrm{X}_{\mathrm{mor}}\right)$ and from glucan to both glucose and GOOs $\left(\% \mathrm{G}_{\mathrm{mor}}\right)$ after HP were computed as follows:

$$
\begin{gathered}
\% X_{\text {mor }}=100\left(\frac{m_{\text {XyloO }}+m_{\text {Xylose }}^{H T}}{m_{\text {Xylan }}^{0}} \frac{1}{F E X}\right)=100\left(\frac{m_{\text {Xylose }}^{\text {AH }}}{m_{\text {Xylan }}^{0}} \frac{1}{F E X}\right) \\
\% G_{m o r}=100\left(\frac{m_{\text {GlucoO }}+m_{\text {Glucose }}^{H T}}{m_{\text {Glucan }}^{0}} \frac{1}{F E G}\right)=100\left(\frac{m_{\text {Glucose }}^{H T}}{m_{\text {Glucan }}^{0}} \frac{1}{F E G}\right)
\end{gathered}
$$




\section{Conclusions}

Laboratory-scale batch HP experiments of WS were conducted under an overall isothermal regime since the heating and cooling stages were carried out in very short periods with a minimum effect on the polymer release. The results of these experiments in terms of xylan and glucan release showed a clear difference with those already reported in the literature for HP at the laboratory scale but are similar to those reported for HP conducted at commercial scales in continuous and isothermal operation.

Author Contributions: Conceptualization, A.S. and E.A.-G.; methodology, F.R.; validation, F.R.; performed the autohydrolysis experiments, A.S.-T.; formal analysis, E.A.-G. and A.S.; investigation, F.R.; resources, A.S. and E.A.-G.; data curation, E.A.-G.; writing-original draft preparation, E.A.-G. and F.R.; writing-review and editing, A.S. and E.A.-G.; supervision, A.S.; project administration, E.A.-G.; funding acquisition, A.S. and E.A.-G. All authors have read and agreed to the published version of the manuscript.

Funding: This research was funded by the Mexican Council of Science and Technology Institutional Fund (CONACYT), grant 247498; the Energy Sustainability Fund 2014-05 (CONACYT-SENER); and the Mexican Bioenergy Innovation Centre, Bioalcohols Consortium (249564).

Institutional Review Board Statement: Not applicable.

Informed Consent Statement: Not applicable.

Data Availability Statement: The data presented in this study are available on request from the corresponding author.

Conflicts of Interest: The authors declare no conflict of interest.

Sample Availability: Samples of the compounds are not available from the authors.

\section{References}

1. Ilanidis, D.; Stagge, S.; Jonsson, L.J.; Martin, C. Hydrothermal pretreatment of wheat straw: Effects of temperature and acidity on byproduct formation and inhibition of enzymatic hydrolysis and ethanolic fermentation. Agronomy 2021, 11, 487. [CrossRef]

2. Mandavgane, S.A.; Kulkarni, B.D. Wheat Straw Valorization: Material Balance and Biorefinery Approach. In Biorefinery Production Technologies for Chemicals and Energy; John Wiley \& Sons: Hoboken, NJ, USA, 2020; pp. 371-381. [CrossRef]

3. Zhang, J.; Zhou, H.; Liu, D.; Zhao, X. Pretreatment of lignocellulosic biomass for efficient enzymatic saccharification of cellulose. In Lignocellulosic Biomass to Liquid Biofuels; Elsevier: Amsterdam, The Netherlands, 2020; pp. 17-65. [CrossRef]

4. Ruiz, H.A.; Conrad, M.; Sun, S.-N.; Sanchez, A.; Rocha, G.J.; Romani, A.; Castro, E.; Torres, A.; Rodriguez-Jasso, R.M.; Andrade, L.P.; et al. Engineering aspects of hydrothermal pretreatment: From batch to continuous operation, scale-up and pilot reactor under biorefinery concept. Bioresour. Technol. 2020, 299, 122685. [CrossRef] [PubMed]

5. Rodríguez, F.; Parra, C.; Sanchez, A. Role of Steam Explosion on Enzymatic Digestibility, Xylan Extraction, and Lignin Release of Lignocellulosic Biomass. ACS Sustain. Chem. Eng. 2017, 5, 5234-5240. [CrossRef]

6. Baruah, J.; Nath, B.K.; Sharma, R.; Kumar, S.; Deka, R.C.; Baruah, D.C.; Kalita, E. Recent trends in the pretreatment of lignocellulosic biomass for value-added products. Front. Energy Res. 2018, 6, 141. [CrossRef]

7. Chen, Q.; Chen, K.; Wang, K.; Ma, J.; Yang, H.; Chen, J. The effects of time and temperature in hydrothermal pretreatment on the enzymatic efficiency of wheat straw. BioRes. 2018, 13, 5193-5203.

8. Steinbach, D.; Kruse, A.; Sauer, J. Pretreatment technologies of lignocellulosic biomass in water in view of furfural and 5hydroxymethylfurfural production-a review. Biomass Conv. Bioref. 2017, 7, 247-274. [CrossRef]

9. Freitas, C.; Carmona, E.; Brienzo, M. Xylooligosaccharides production process from lignocellulosic biomass and bioactive effects. Bioact. Carbohydr. Diet. Fibre 2019, 18, 100184. [CrossRef]

10. Capetti, C.C.; Vacilotto, M.M.; Dabul, A.N.G.; Veiga, A.G.; Arnoldi, V.O.; Polikarpov, I. Recent advances in the enzymatic production and applications of xylooligosaccharides. World J. Microb. Biotechnol. 2021, 37, 169. [CrossRef]

11. Sidiras, D.; Batzias, F.; Ranjan, R.; Tsapatsis, M. Simulation and optimization of batch autohydrolysis of wheat straw to monosaccharides and oligosaccharides. Bioresour. Technol. 2011, 102, 10486-10492. [CrossRef]

12. Ruiz, H.A.; Vicente, A.A.; Teixeira, J.A. Kinetic modeling of enzymatic saccharification using wheat straw pretreated under autohydrolysis and organosolv process. Ind. Crops. Prod. 2012, 36, 100-107. [CrossRef]

13. Silva-Fernandes, T.; Duarte, L.C.; Carvalheiro, F.; Marques, S.; LoureiroDias, M.C.; Fonseca, C.; Girio, F. Biorefining strategy for maximal monosaccharide recovery from three different feedstocks: Eucalyptus residues, wheat straw and olive tree pruning. Bioresour. Technol. 2015, 183, 203-212. [CrossRef] [PubMed] 
14. Rossberg, C.; Steffien, D.; Bremer, M.; Koenig, S.; Carvalheiro, F.; Duarte, L.C.; Moniz, P.; Hoernicke, M.; Bertau, M.; Fischer, S. Pulp properties resulting from different pretreatments of wheat straw and their influence on enzymatic hydrolysis rate. Bioresour. Technol. 2014, 169, 206-212. [CrossRef] [PubMed]

15. Prunescu, R.M.; Blanke, M.; Jakobsen, J.G.; Sin, G. Dynamic modeling and validation of a biomass hydrothermal pretreatment process-a demonstration scale study. AIChE J. 2015, 61, 4235-4250. [CrossRef]

16. Rodriguez, F.; Sanchez, A.; Amaya-Delgado, L. Xylooligosaccharides production from lignocellulosic biomass using a pilot-scale pretreatment continuous tubular reactor: Modelling and experimental validation. Ind. Crops Prod. 2019, 134, 62-70. [CrossRef]

17. Makishima, S.; Mizuno, M.; Sato, N.; Shinji, K.; Suzuki, M.; Nozaki, K.; Takahashi, F.; Kanda, T.; Amano, Y. Development of continuous flow type hydrothermal reactor for hemicellulose fraction recovery from corncob. Bioresour. Technol. 2009, 100, 2842-2848. [CrossRef]

18. Sievers, D.A.; Stickel, J.J. Modeling residence-time distribution in horizontal screw hydrolysis reactors. Chem. Eng. Sci. 2018, 175, 396-404. [CrossRef]

19. Jaramillo, I.; Sanchez, A. Mass Flow Dynamic Modeling and Residence Time Control of a Continuous Tubular Reactor for Biomass Pretreatment. ACS Sustain. Chem. Eng. 2018, 6, 8570-8577. [CrossRef]

20. Yue, P.; Hu, Y.; Tian, R.; Bian, J.; Peng, F. Hydrothermal pretreatment for the production of oligosaccharides: A review. Bioresour. Technol. 2022, 343, 126075. [CrossRef]

21. Ruiz, H.A.; Galbe, M.; Garrote, G.; Ramirez-Gutierrez, D.M.; Ximenes, E.; Sun, S.N.; Lachos-Perez, D.; Rodríguez-Jasso, R.M.; Sun, R.C.; Yang, B.; et al. Severity factor kinetic model as a strategic parameter of hydrothermal processing (steam explosion and liquid hot water) for biomass fractionation under biorefinery concept. Bioresour. Technol. 2021, 342, 125961. [CrossRef]

22. Ilanidis, D.; Stagge, S.; Jönsson, L.J.; Martín, C. Effects of operational conditions on auto-catalyzed and sulfuric-acid-catalyzed hydrothermal pretreatment of sugarcane bagasse at different severity factor. Ind. Crops Prod. 2021, 159, 113077. [CrossRef]

23. Yu, A.; Zhang, B.; Yu, F.; Xu, G.; Song, A. A real explosion: The requirement of steam explosion pretreatment. Bioresour. Technol. 2012, 121, 335-341. [CrossRef] [PubMed]

24. Conrad, M.; Häring, H.; Smirnova, I. Design of an industrial autohydrolysis pretreatment plant for annual lignocellulose. Biomass Conv. Bioref. 2019, 11, 2293-2310. [CrossRef]

25. Zhang, B.; von Keitz, M.; Valentas, K. Thermal Effects on Hydrothermal Biomass Liquefaction. In Biotechnology for Fuels and Chemicals; Adney, W.S., McMillan, J.D., Mielenz, J., Klasson, K.T., Eds.; Humana Press: Totowa, NJ, USA, 2008; pp. 511-518. [CrossRef]

26. Yu, J.; Paterson, N.; Blamey, J.; Millan, M. Cellulose, xylan and lignin interactions during pyrolysis of lignocellulosic biomass. Fuel 2017, 191, 140-149. [CrossRef]

27. Trajano, H.L.; DeMartini, J.D.; Studer, M.H.; Wyman, C.E. Comparison of the effectiveness of a fluidized sand bath and a steam chamber for reactor heating. Ind. Eng. Chem. Res. 2013, 52, 4932-4938. [CrossRef]

28. Shi, J.; Pu, Y.; Yang, B.; Ragauskas, A.; Wyman, C.E. Comparison of microwaves to fluidized sand baths for heating tubular reactors for hydrothermal and dilute acid batch pretreatment of corn stover. Bioresour. Technol. 2011, 102, 5952-5961. [CrossRef]

29. Carvalheiro, F.; Silva-Fernandes, T.; Duarte, L.C.; Girio, F.M. Wheat straw autohydrolysis: Process optimization and products characterization. Appl. Biochem. Biotechnol. 2008, 153, 84-93. [CrossRef]

30. Pérez Pimienta, J.A.; Papa, G.; Gladden, J.M.; Simmons, B.A.; Sanchez, A. The effect of continuous tubular reactor technologies on the pretreatment of lignocellulosic biomass at pilot-scale for bioethanol production. RSC Adv. 2020, 10, 8147-18159. [CrossRef]

31. Gonzalez-Rios, J.A.; Valle-Pérez, A.U.; Amaya-Delgado, L. A quick fed-batch saccharification strategy of wheat straw at high solid loadings improving lignocellulosic ethanol productivity. Biomass Conv. Bioref. 2021, 1-13. [CrossRef]

32. Lopez-Hidalgo, A.M.; Magaña, G.; Rodriguez, F.; Leon-Rodriguez, A.D.; Sanchez, A. Co-production of ethanol-hydrogen by genetically engineered Escherichia coli in sustainable biorefineries for lignocellulosic ethanol production. Chem. Eng. J. 2021, 406, 126829. [CrossRef]

33. Pérez Pimienta, J.A.; Papa, G.; Rodriguez, A.; Barcelos, C.A.; Liang, L.; Stavila, V.; Sanchez, A.; Gladden, J.M.; Simmons, B.A. Pilot-scale hydrothermal pretreatment and optimized saccharification enables bisabolene production from multiple feedstocks. Green Chem. 2019, 21, 3152-3164. [CrossRef]

34. Sluiter, A.; Ruiz, R.; Scarlata, C.; Sluiter, J.; Templeton, D. Determination of extractives in biomass. In Technical Report; NREL: Golden, CO, USA, 2008.

35. Rojas-Rejon, O.A.; Sanchez, A. The impact of particle size and initial solid loading on thermochemical pretreatment of wheat straw for improving sugar recovery. Bioprocess. Biosyst. Eng. 2014, 37, 1427-1436. [CrossRef] [PubMed]

36. Yang, B.; Wyman, C.E. Characterization of the degree of polymerization of xylooligomers produced by flowthrough hydrolysis of pure xylan and corn stover with water. Bioresour. Technol. 2014, 99, 5756-5762. [CrossRef] 